\title{
21. Epilogue: Sifting the silence
}

\author{
Margo Neale, Project Director,
} Barks, Birds \& Billabongs symposium

It is now more than 60 years since the American-Australian Scientific Expedition team embarked upon their pioneering adventure into Arnhem Land-a region that was still recorded on some maps at the time as 'largely unexplored'. Mounting this 17-person, seven-month odyssey in the postwar period, with 47 tonnes of equipment and provisions, was a herculean effort. Despite thisand the enormous media and scientific attention and support it received at the time - very little is known of this Expedition today. Few, if any, efforts had been made in the intervening six decades to revisit and re-evaluate its significance. It appears to have been mysteriously buried, or, as Yolngu people might say, it has gone 'inside'. While a small number of individuals connected to the event personally, professionally or institutionally might have had varying degrees of awareness or knowledge of the Expedition, many Yolngu and Bininj communities have an acute interest in it, kept alive through oral traditions. The Barks, Birds \& Billabongs Symposium brought this overlooked moment in Australian history back into the light, to the 'outside'.

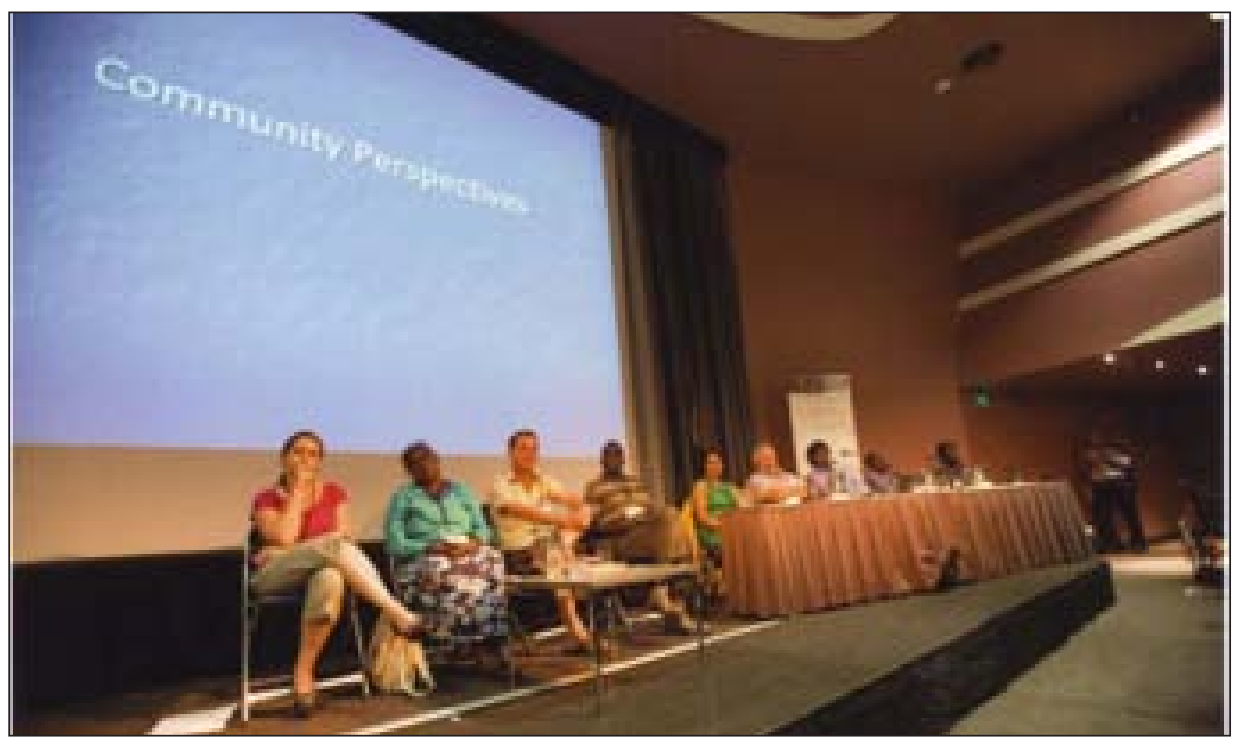

Figure 21.1 Sally May, Donna Nadjamerrek, Anthony Murphy, Jeffrey Dharramanydji, Lori Richardson, Steve Webb, Thomas Amagula, Wilfred Nawirridj and Wukan Wanambi on the Community Perspective panel at the symposium, 2009 


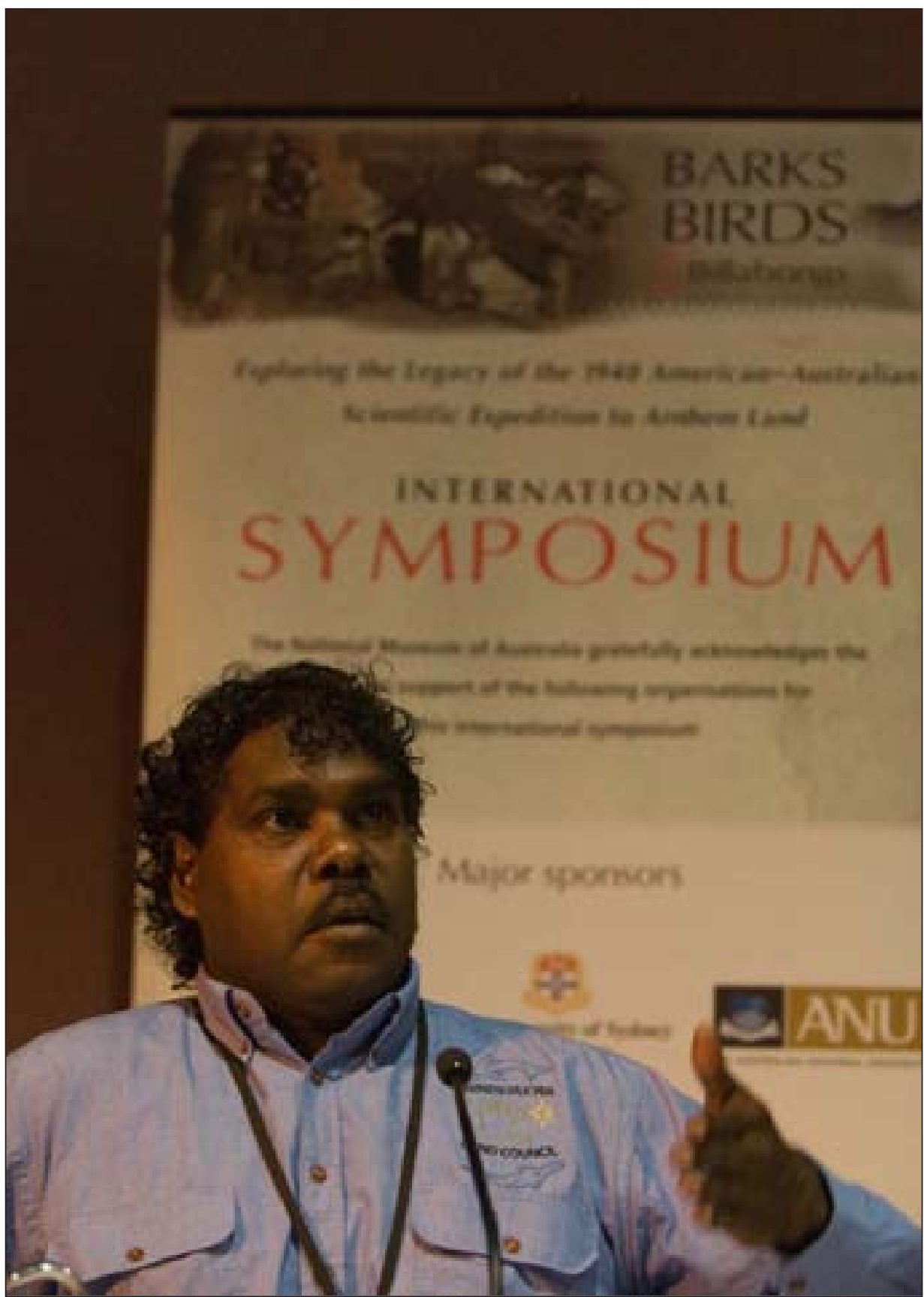

Figure 21.2 Thomas Amagula, 2009

Photograph by George Serras 
Embarking on the symposium was not unlike an archaeological dig. We dusted off layers of accumulated, quasi-institutionalised forgetting; revived the memories of the handful of remaining Expedition members and their relatives; retrieved the archival past; and gave voice to those who were largely unheard in 1948. The centrality of Indigenous voices directly or indirectly during this symposium provided a partial, but necessary, rectification of the marginalisation of Indigenous perspectives six decades ago. What made this symposium particularly exciting was that no-one could foresee what would be uncovered in the process of deep-coring that took place. Already, collections from the Arnhem Land Expedition were being rediscovered: film footage at the Smithsonian Institution; paintings on paper at the State Library of South Australia archived among manuscripts; orphaned objects at the National Museum of Australia in Canberra; as well as Indigenous accounts of the Expedition, previously unheard outside the community.

The salvage mentality that motivated these scientific and cultural explorers decades ago is having some unintended positive consequences today. The socalled passive subjects of study in 1948 (or at least their descendants) have now become beneficiaries of it in ways that were explored at the symposium. With the rise of knowledge centres in Arnhem Land communities, there has been a transfer of knowledge to the people whose culture and environment were the subjects of study. Images of objects collected in 1948 were received - not as relics of the past, but in a way that saw their reanimation as part of a continuing and changing contemporary culture. Attitudinal changes in research protocols, in social context, in the nature of history telling, and issues of who owns the past, were re-examined. A contingent of some 25 Arnhem Landers, representing each of the three official Expedition sites, participated in the event and conducted a number of Indigenous panels dealing with repatriation of objects and knowledge.

On the Politics of Repatriation panel, the community members made the brave decision to show sensitive footage of the collection of human remains by the American archaeologist Frank Setzler, from burial sites at Arrkuluk Hill in Western Arnhem Land. They wanted people at the symposium to see this disturbing footage so that they would know what actually happened and understand why Aboriginal people are distressed and need their 'old people' returned to country. As Wilfred Nawirridj said, 'nobody should interfere- noone should muck around - with these bones. They've been through ceremony... We hold dear these practices.' He went on to say: 'It's very sad to us...that our ancestors...never sleep very well, these remains. Night and day...they used to keep moving upside down, scratching.' 


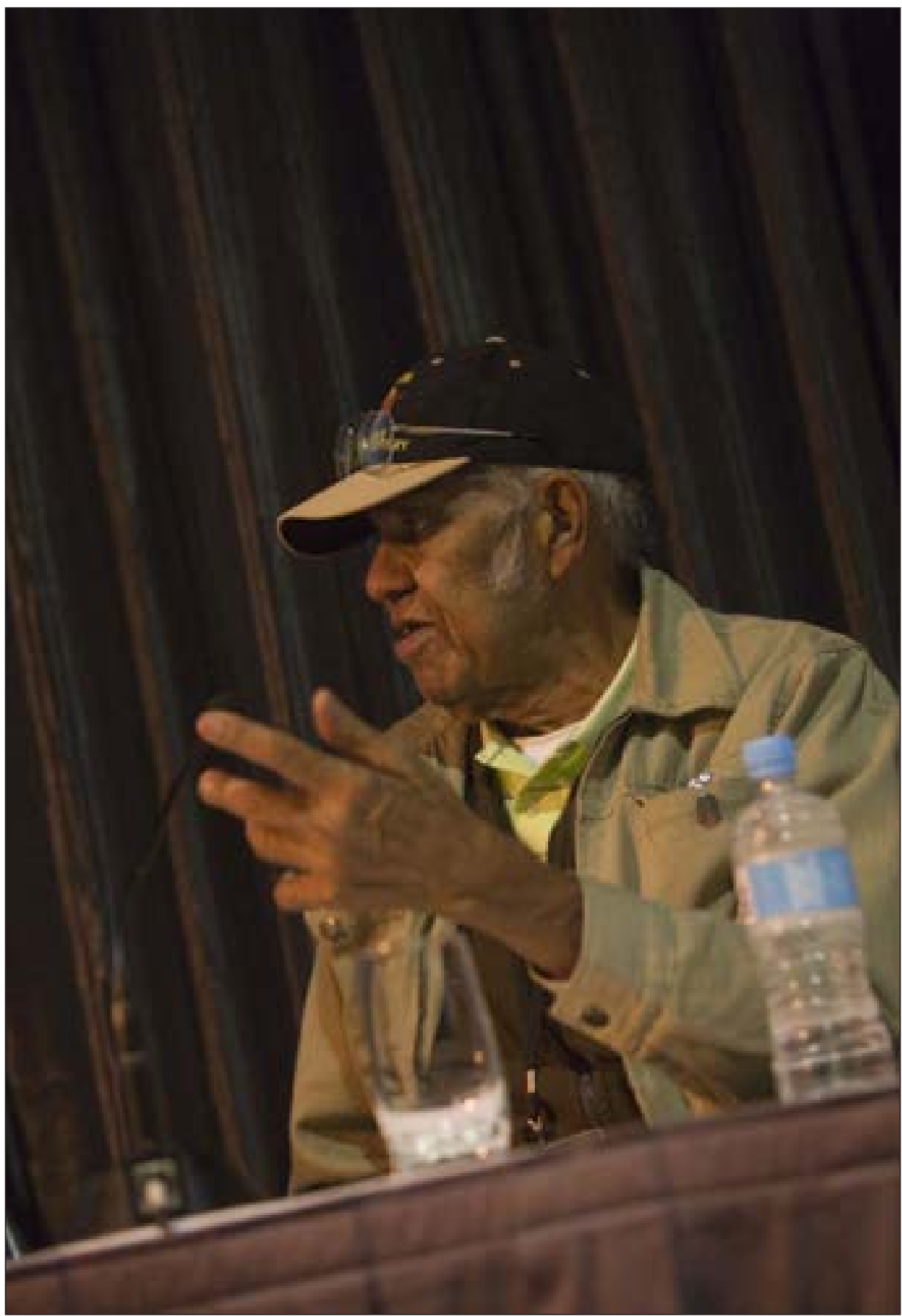

Figure 21.3 Donald Blitner, 2009

Photograph by George Serras 


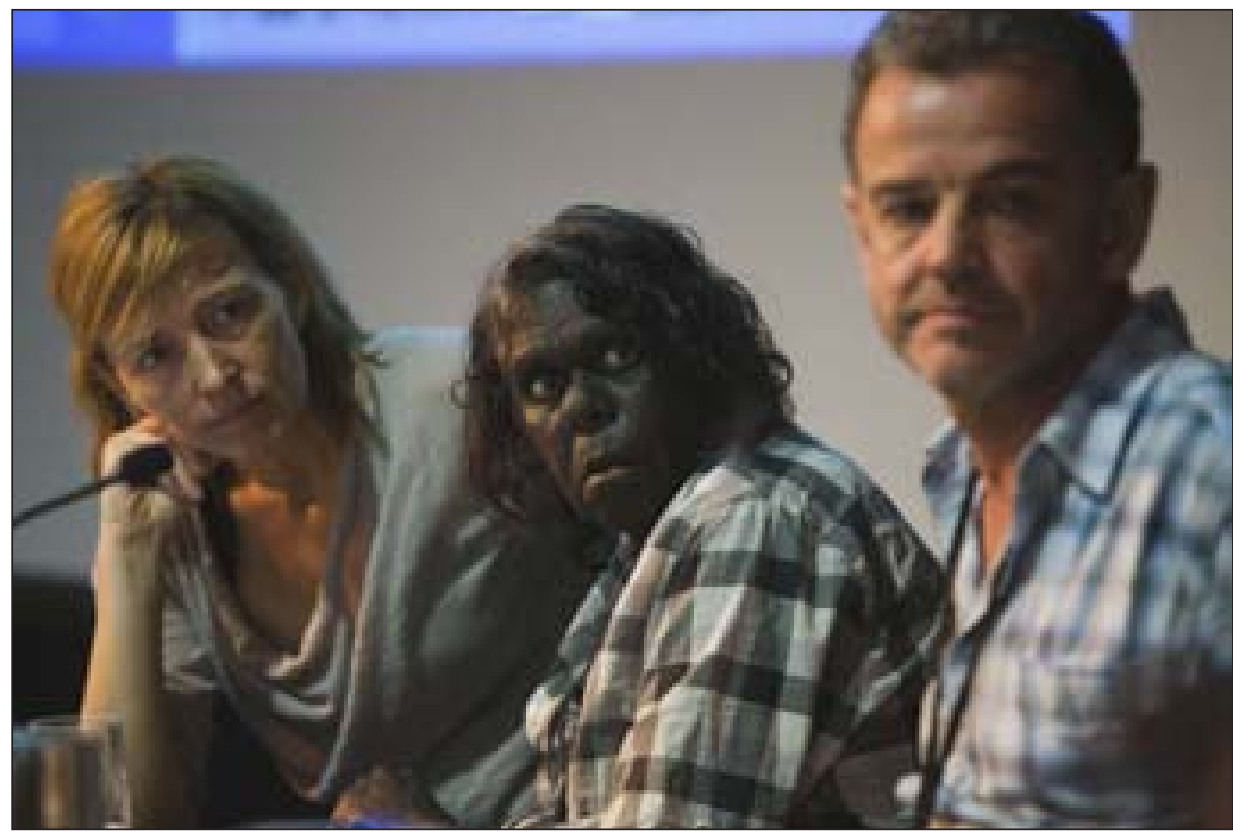

Figure 21.4 Politics of Repatriation panel: Sabine Hoeng, Joy Williams and Anthony Murphy, 2009

Photograph by George Serras

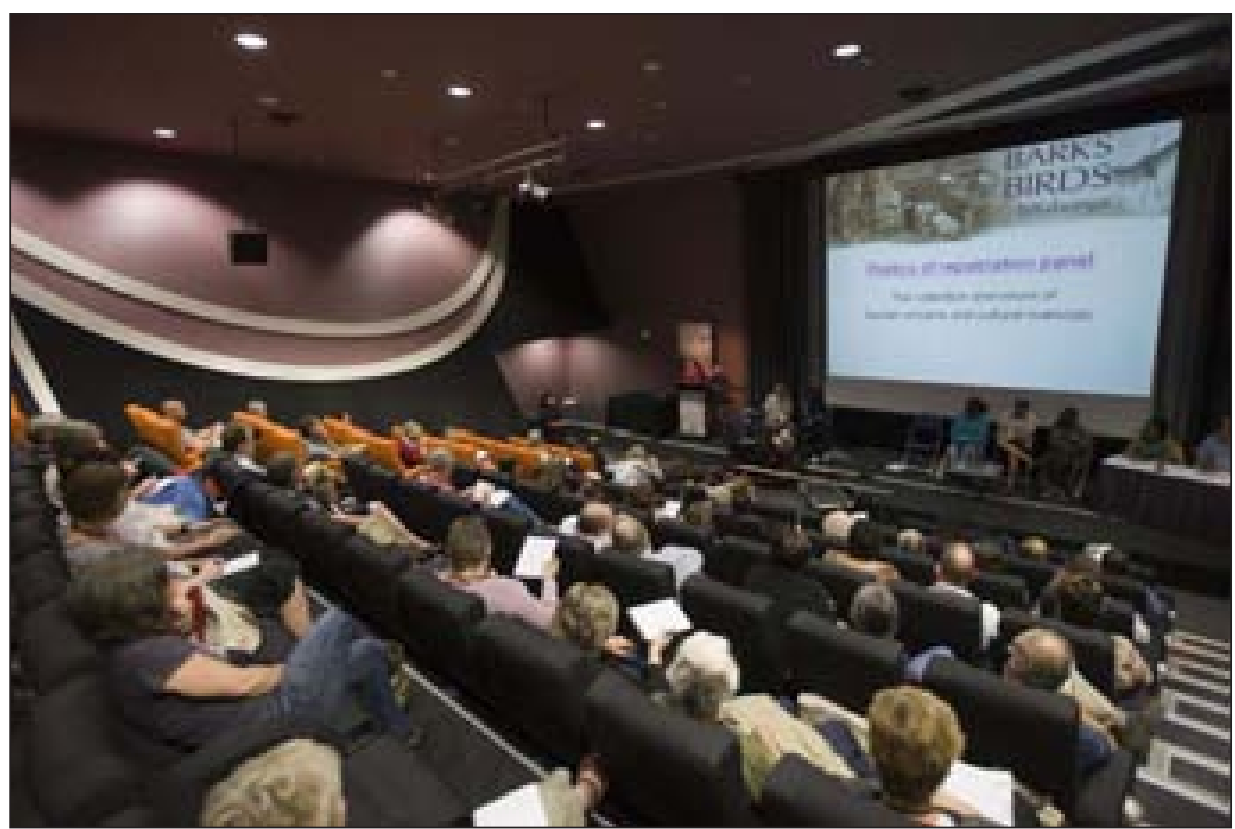

Figure 21.5 Audience at the Politics of Repatriation panel discussion, 2009

Photograph by George Serras 


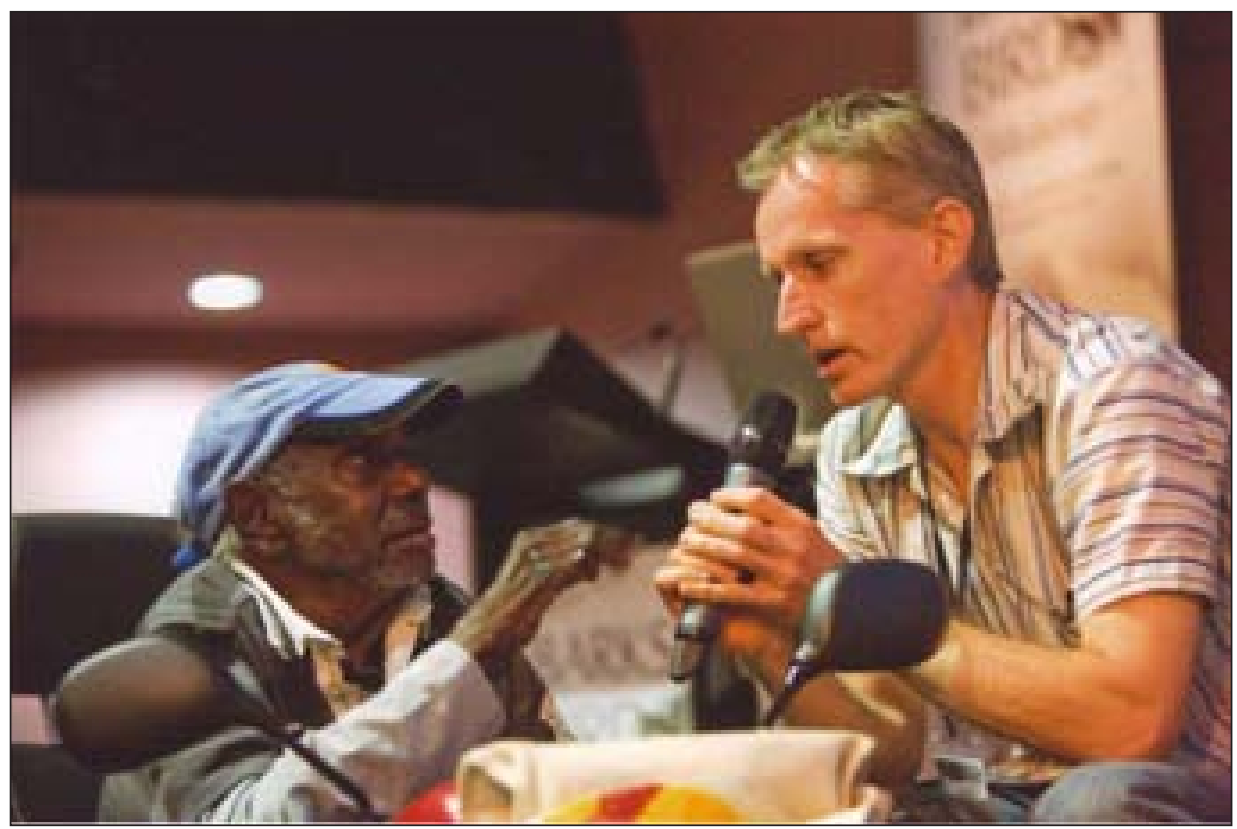

Figure 21.6 Jimmy Kalarriya Namarnyilk and Murray Garde, 2009

Photograph by George Serras

Joe Gumbula from Galiwinku, who has been active in lobbying the Smithsonian Institution, talked about how the clans feel responsible for not protecting their old people from being taken: 'It is a danger for us because of that thing and it's killing our people.'

Fears were also expressed about the cultural responsibilities they have when only some of the remains are returned; the anguish they feel when they have to leave other 'old people' behind. What do you do with the remains when they get back to the community? They have already gone through ceremony. What is the ceremony you do when you take them back, and where do you bury them?

Steve Webb, a physical anthropologist from Bond University, reflected the forward-thinking tone of the group when he emphasised the need to move on: 'This is not the time to condemn this institution or that institution. It's not the time to condemn people that took them...they were creatures of their own generation. But we're creatures of ours.' 


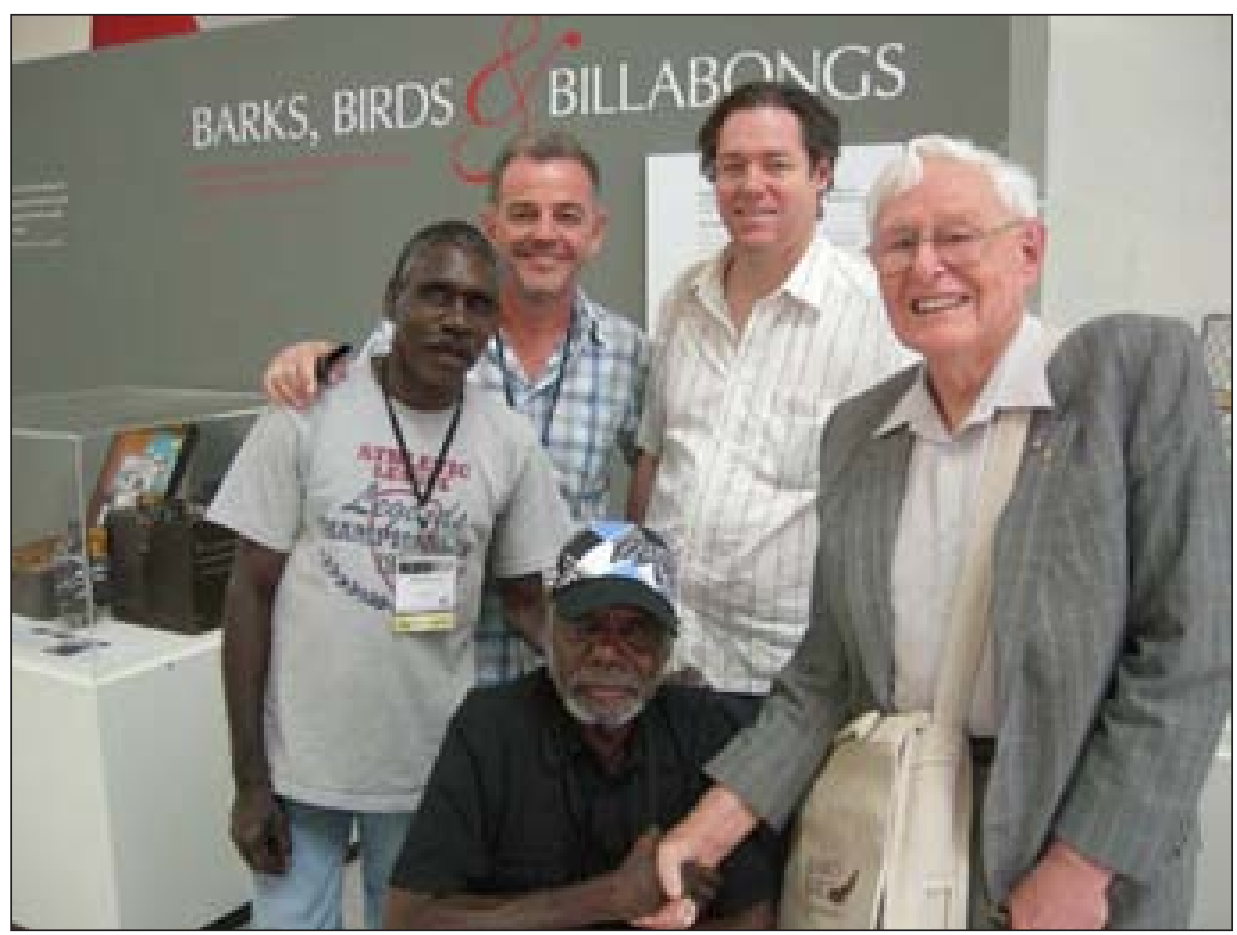

Figure 21.7 Wilfred Nawirridj, Anthony Murphy and Jimmy Kalarriya Namarnyilk (seated) from Gunbalanya community, Martin Thomas and Expedition participant Raymond Specht pose in front of a display of objects from the Expedition, 2009

\section{Photograph by George Serras}

The day before the symposium launch there was a reunion of Aboriginal and nonAboriginal descendants, and others closely involved with the 1948 Expedition in which a rare and electrifying engagement took place-an engagement in which history and memory intersected in the most human of occasions. Gathered together were one of the two surviving expeditioners, eighty-fouryear-old Raymond Specht, and his family; the adult children of Gerald Blitner and other descendants from Groote Eylandt; the grandchildren of Charles P. Mountford; and relatives of many others - Indigenous and non-Indigenouswho intersected with the Expedition, including Joe Gumbulu from Galiwinku, Thomas Amagula from Groote Eylandt Jimmy Kalarriya Namarnyilk and Donna Nadjamerrek from Gunbalanya, and Naminapu Maymuru from Yirrkala. As a silent National Geographic Society film tracing the Expeditioners' exploits from community to community rolled, a microphone was passed around the room capturing a running commentary by those able to flesh out the story, put names to previously unnamed Aboriginal people and explain the 'old ways' depicted. Stories were heard through their fathers and grandfathers, which have not 
been recorded in history books, and connections were made and remade. What transpired over the afternoon was a remarkable, impromptu and dynamic piece of history telling from both sides of the 'frontier'. It was indeed history making.

So intent were the expeditioners on conducting a 'search and rescue' mission for an imagined static culture on the brink of extinction that they collected with rear-view vision. In hindsight, this has proven to be advantageous in many ways, providing baseline studies not only in the sciences and humanities, but also in the study of black/white relations, changing research protocols and museological practices. From the vantage point of the symposium in 2009, it became clear what they did not see - or at least could not understand: that Aboriginal people were already on the frontier of cross-cultural exchange and were not the remnants of the Stone Age they imagined. Furthermore, the expeditioners could not comprehend that they were themselves part of the narrative of outsiders who were active agents in the processes of accommodation and resistance that Arnhem Landers were engaged in. While the expeditioners themselves were trying to resist and adjust to 'natives who were becoming too civilised' for their studies, their 'subjects' were dealing with cultural preservation in a different way in the face of researchers, missionaries, adventurers and government personnel.

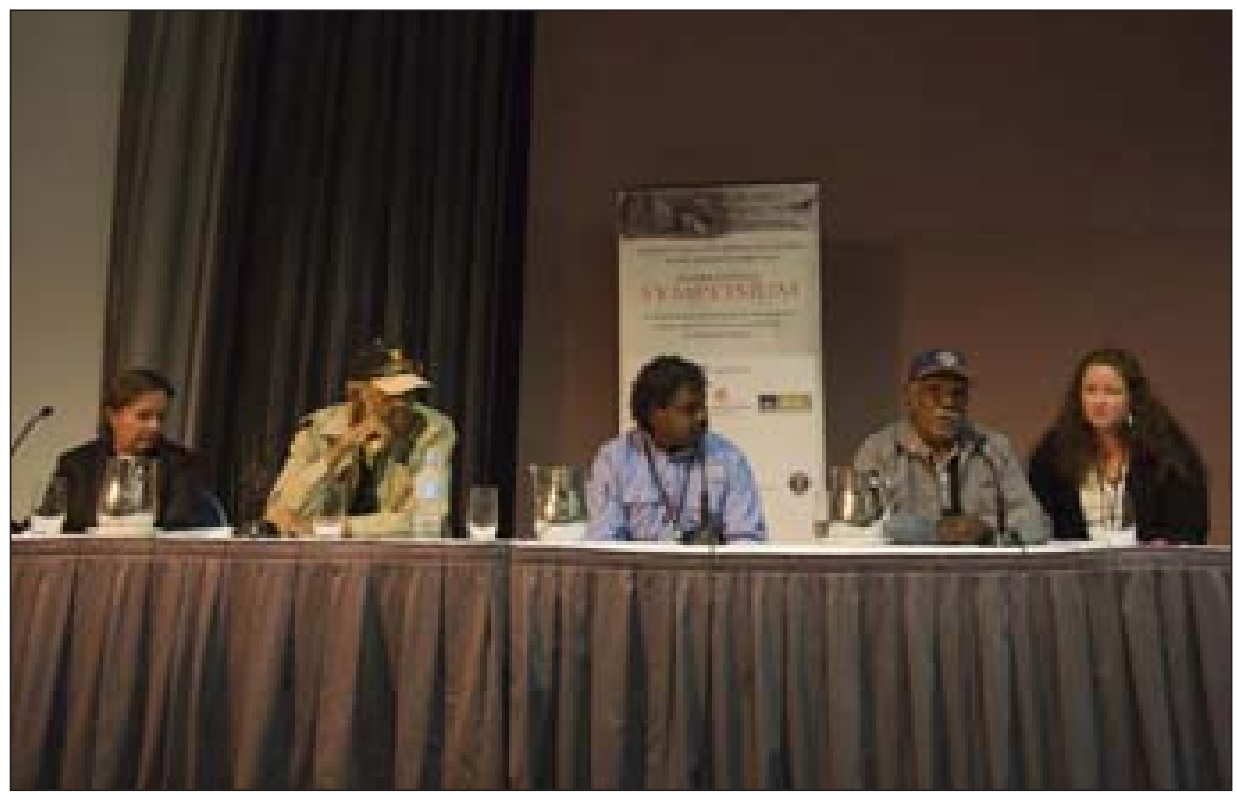

Figure 21.8 Annie Clarke, Donald Blitner, Thomas Amagula, Jabani Lalara and Brooke Rankmore, 2009

Photograph by George Serras 
These and other intriguing narratives explored during the symposium provided new perspectives, interpretations and understandings. New growth rings were added to the Expedition and its legacy, such as an opportunity to acknowledge and celebrate the intellectual property, skills and Indigenous knowledge systems of the Arnhem Landers instead of only the ingenuity and expertise of the Western expeditioners, as was customary.

If the symposium was similar to an archaeological dig in relation to the past, in terms of the future, it was more akin to the opening of Pandora's Box, where new and unexamined ideas were inadvertently released to fertilise future ventures and collaborations, a number of which are already taking form and gathering momentum. These include collaboration with the Smithsonian Institution for an online research portal to unite the dispersed Arnhem Land Expedition collections and to share documentation. That is, to digitally reunite the significant holdings at the Smithsonian Institution in Washington, DC, the National Museum of Australia, the South Australian Museum, the Australian Museum and other places. This long-term project will not only enable researchers from around the world to access this hitherto inaccessible collection but, most significantly, it will enable Aboriginal communities to access their cultural heritage through the many knowledge centres that exist across Arnhem Land. It is a two-way process whereby access to the objects digitally will also stimulate Aboriginal people to augment the documentation that currently exists about this collection by humanising the objects with the names of makers, their clan associations and kinship relationships to living relatives - a big issue with older collections of this period. This reclamation process, through naming, was taking place at the symposium as archival images and footage were rolled out over the course of the week. Descendants were deeply moved at seeing their forebears and the way they practised culture 60 years ago. Some expressed this reconnection as 'bringing them [the people] back to life for us' or 'teaching us old ways again, which we can use to teach others'. The footage effectively became a training manual and a vehicle for remembering proudly. They expressed great pride in their cultural material and wanted copies of images from the Expedition archives for their knowledge centres. Another mooted collaboration is an international touring exhibition of the ethnological collection between the National Museum of Australia, the Australian National University, the Smithsonian Institution and possibly others.

Some years ago I planned to mount a collaborative touring international exhibition using collections from the 1948 Arnhem Land Expedition, with a particular focus on the ethnographic/art materials. I soon discovered that such a project would be an enormous and almost impossible enterprise, given the locations of diverse collections and the dissipation of knowledge and interest over the years. To undertake such a venture, and give due justice to the scale 
and significance of the Arnhem Land Expedition, and to recapture something of the collaborative spirit of the original project, I would need to pull together all the knowledge holders, in particular the original players and their descendants or current representatives-across cultures, across continents and across disciplines. This symposium was the beginning of that process. It was the opening conversation.

To facilitate this conversation, the symposium was kept relatively contained in terms of speakers and audience numbers. There were no parallel sessions, extraneous entertainment offerings, or keynote speakers. Instead, I aimed to stimulate dialogue between and amongst the speakers and the audience, to create an expanded workshop model. Speakers had already been talking to each other and their papers were exchanged in advance of the symposium to allow more informed discussions and new linkages to develop. Symposium delegates were in one venue throughout the three days of formal proceedings, which allowed continuity between sessions and an accumulation of knowledge over a full week of workshops, performances and meetings.

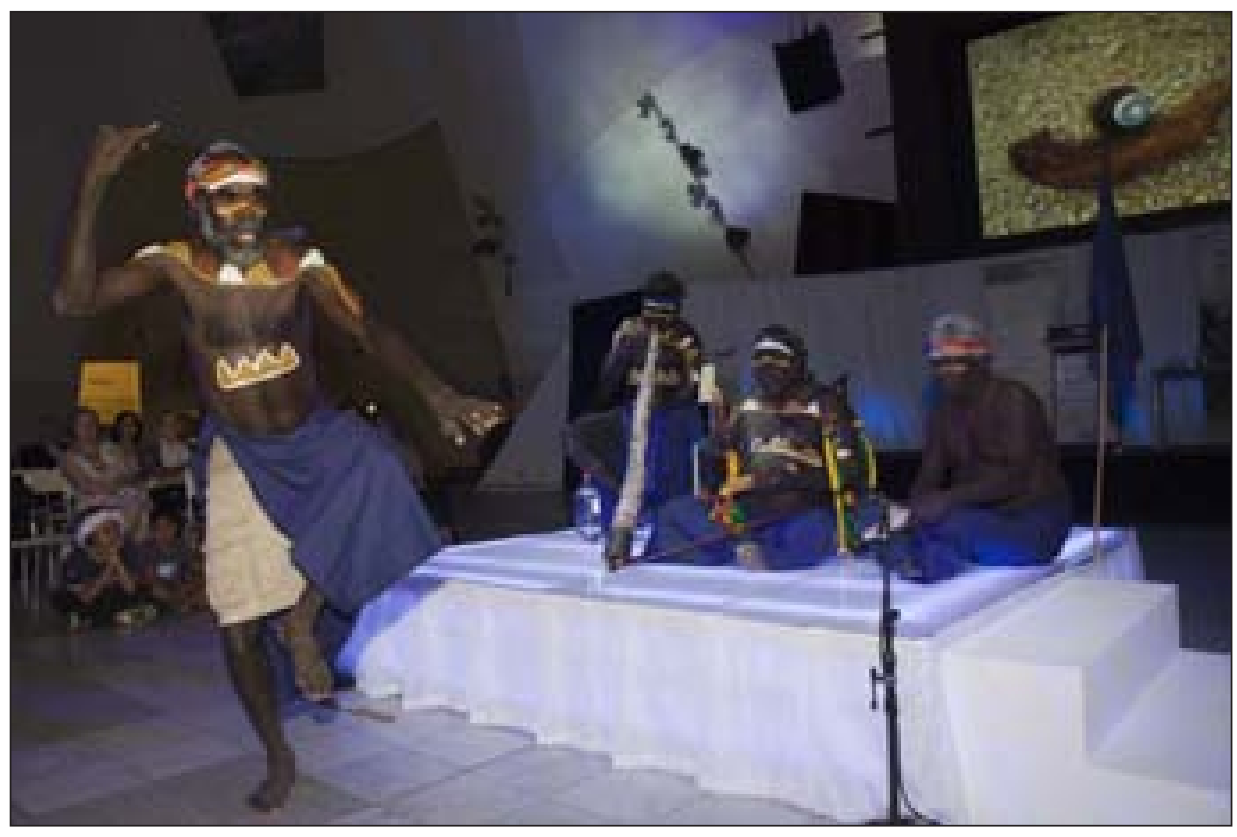

Figure 21.9 Manimawuy Dhamarrandji, Djombala Dhamarrandji, Djangirrawuy Garawirrtja and Joe Neparrnga Gumbula performing the Manikay Currents from a Distant Shore: Birrkili Yolngu songs of Makassan contact in north-east Arnhem Land at the National Museum of Australia, 2009

Photograph by George Serras 


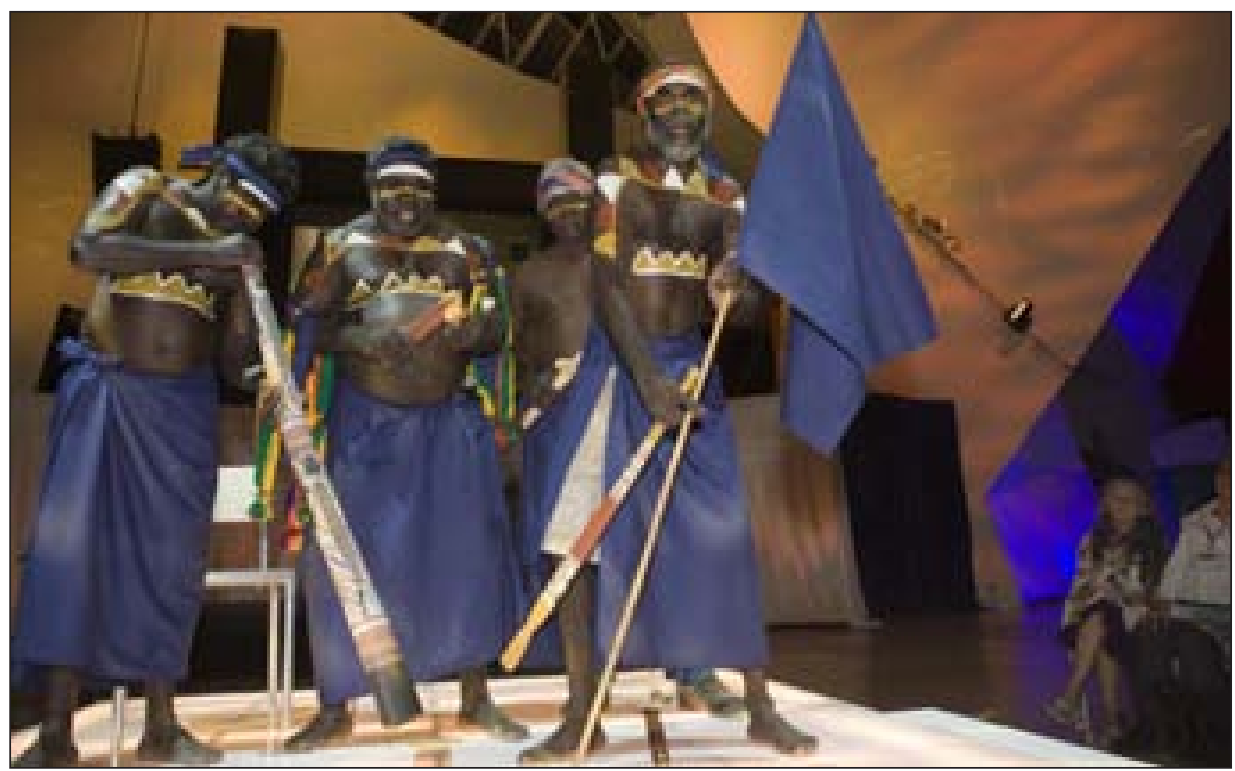

21.10 Djombala Dhamarrandji, Djangirrawuy Garawirrtja, Joe Neparrnga Gumbula and Manimawuy Dhamarrandji performing the Manikay Currents from a Distant Shore: Birrkili Yolngu songs of Makassan contact in northeast Arnhem Land at the National Museum of Australia, 2009

Photograph by George Serras

For the Museum, one of the greatest values in staging this symposium was to further our commitment to reconnecting Indigenous communities with overseas collections, to recovering voices and to stimulating future research. One of the most dramatic and unexpected results of the symposium was news that the Smithsonian was prepared to repatriate further human remains from Arnhem Land. Despite repeated lobbying by numerous delegations from Australian government and community organisations, the institution had remained trenchant in its determination to retain the final third of its original holdings. Yet within weeks of the symposium, they took the initiative, offering to release the remains. I believe this was a case of the power of soft diplomacy over political pressure. Representatives from the Smithsonian in the audience were able to experience the human dimension of the impact of missing ancestral remains, as community members spoke of their distress at the loss, and the shame they felt at not being able to save their 'old people'. Another unexpected outcome was the offer of a short-term placement at the Smithsonian for an Aboriginal trainee, Rebecca Richards, who was working on the National Museum's collection of paintings on bark and cardboard from the Arnhem Land Expedition. She continued this work on the Smithsonian's collection of paintings from the Arnhem Land Expedition. She has since gone out to become Australia's first Indigenous Rhodes Scholar. 


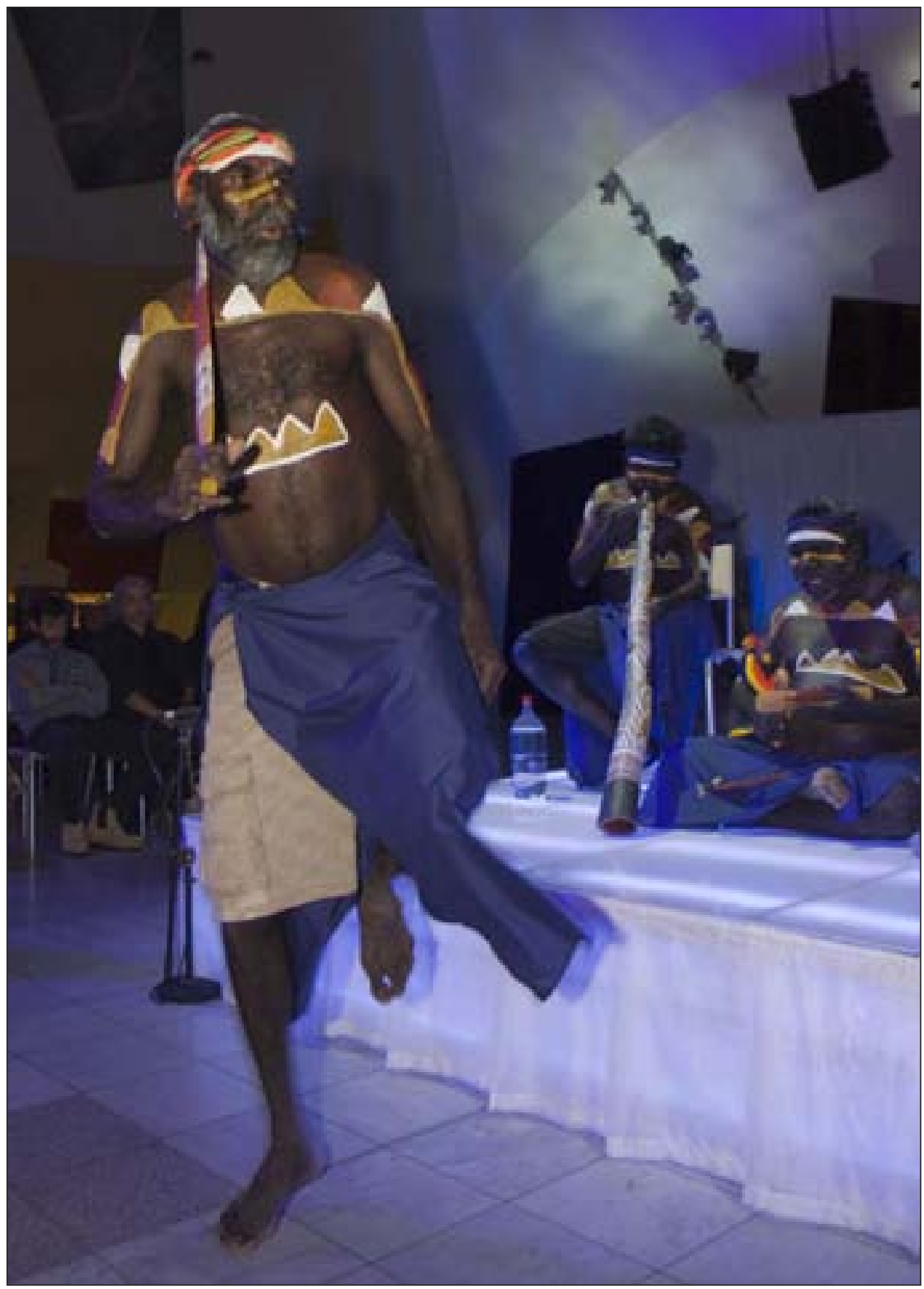

21.11 Manikay performance Currents from a Distant Shore: Birrkili Yolngu songs of Makassan contact in north-east Arnhem Land at the National Museum of Australia, 2009

Photograph by George Serras 


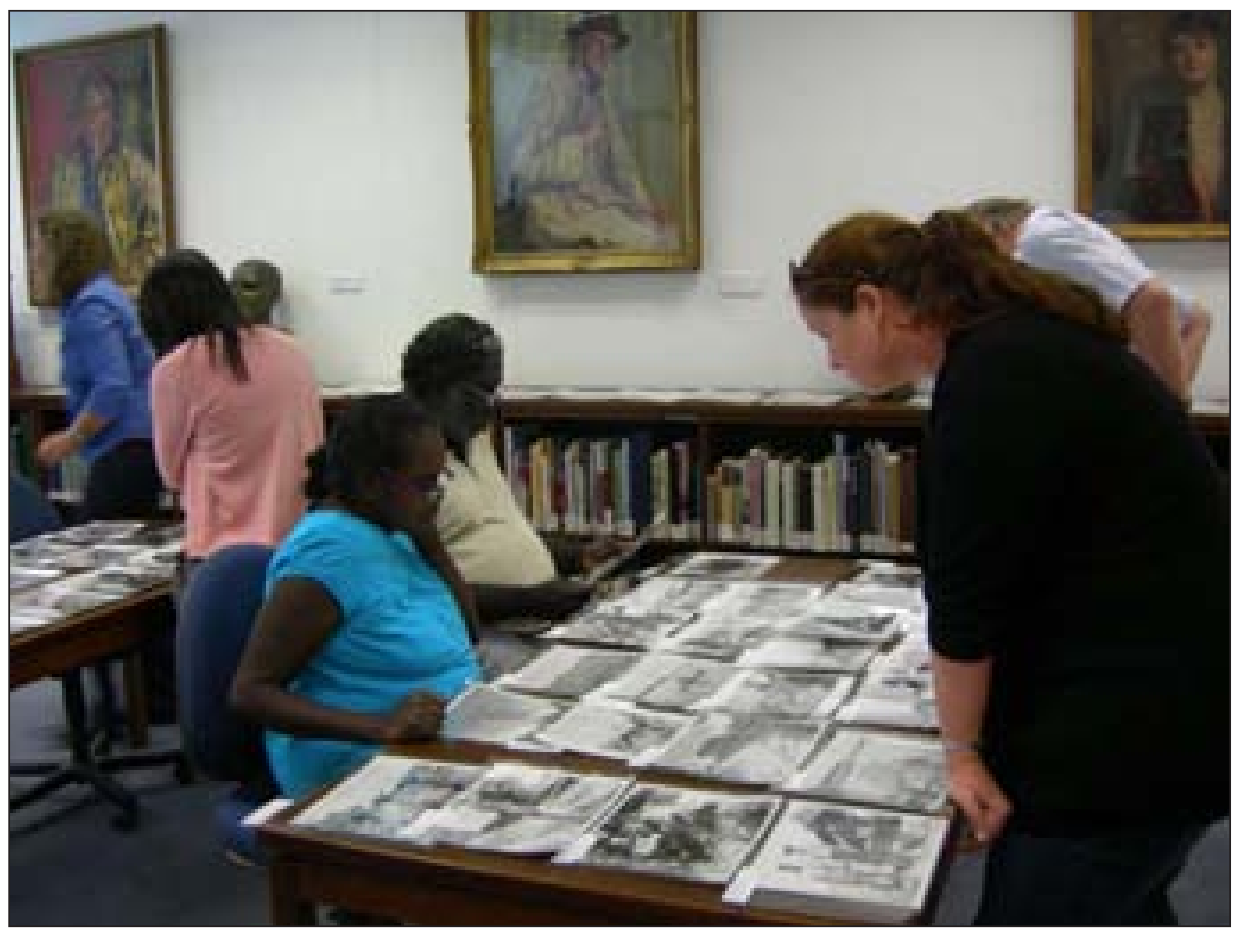

Figure 21.12 Rita and Wukun Wanambi from Yirrkala and Brooke Rankmore from Groote Eylandt look over old photos at the National Library of Australia as part of the symposium's program for connecting communities with collections, 2009

Photograph by Chrischona Schmidt

An aspect of the symposium - widely noted by all involved - was the degree of respect shown to each other across generations and cultures. Given the highly sensitive subjects under discussion, the charged emotional atmosphere and the potential for political volatility, this was truly remarkable. Perhaps it was due to the quality of the human encounters that took place and the depth of engagement. Participants from such diverse fields, countries and age groups found that there was no place for disciplinary baggage, strategic allegiances and party lines. This was not a symposium about ideas or issues that could be held at arm's length for intellectual scrutiny.

When Charles P. Mountford was asked by the National Geographic Society in 1946 if he had an idea worthy of support, he replied, 'I've got more ideas than a dog's got fleas'. In a similar vein, Barks, Birds \& Billabongs abounded with enough new ideas to satisfy even Mountford's expectations. 


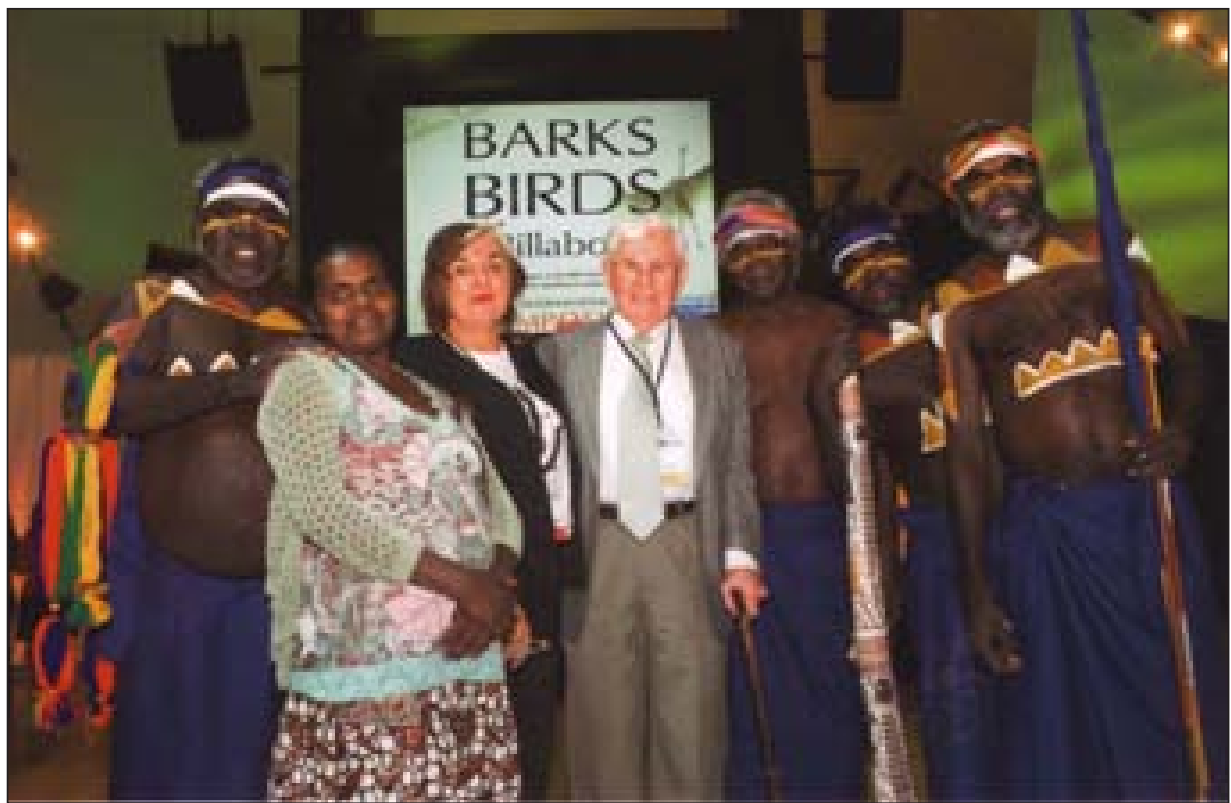

Figure 21.13 Djangirrawuy Garawirrtja, Renelle Buniyi, Margo Neale, Raymond Specht, Joe Neparrnga Gumbula, Djombala Dhamarrandji and Manimawuy Dhamarrandji at the symposium, 2009

Photograph by George Serras 